\title{
Síndrome de Guillain-Barré: ¿la punta del iceberg de un problema mayor?
}

\author{
Guillain-Barré syndrome: could be the tip of the iceberg of a bigger problem?
}

\author{
Aland Bisso-Andrade'
}

\author{
Bisso-Andrade A. Síndrome de Guillain-Barré: jla \\ punta del iceberg de un problema mayor? (Editorial). \\ Rev Soc Peru Med Interna. 2019;32(2):43-44. \\ https://doi.org/10.36393/spmi.v32i2.215
}

A fines del mes de mayo de 2019, en medio de abrumadoras noticias políticas y nuevos destapes de corrupción, los medios de prensa anunciaron que varios centros de salud notificaban casos de síndrome de Guillain-Barré (SGB) en una incidencia fuera de lo acostumbrado. Casi lo mismo ocurrió en 2018. Después de haberse reportado solo 25 casos en 2016 y 59 en 2017, en 2018 este trastorno ocupó las primeras páginas porque la cifra total se elevó hasta 258 , según la estadística oficial del Minsa. ${ }^{1}$

Y, en 2019 no podía ser diferente: a fines de mayo ya se había notificado 57 casos y para el 13 de junio el acumulado fue de 622, tal como aparece en la Sala Virtual de Situación Epidemiológica del Minsa. ${ }^{2}$ Como era de esperar, tratándose de una patología que genera parálisis y es potencialmente mortal, la noticia causó zozobra en la población y el Estado emitió un Decreto Supremo de Emergencia Sanitaria. ${ }^{3}$

El manejo de estos pacientes es costoso debido a que requieren administración de inmunoglobulinas o de plasmaféresis, y en caso de presentar insuficiencia respiratoria se requiere de ventilación mecánica en una unidad de cuidados intensivos con toda la logística adicional que ello requiere. Similar al año anterior, muchas autoridades políticas y de Salud, así como especialistas en el tema, inundaron las redes sociales y los medios de comunicación con opiniones de diverso calibre: desde testimonios serios, ponderados y con la debida argumentación científica hasta aquellos que utilizando un lenguaje almibarado y apocalíptico pontificaban sobre la enfermedad sin el mínimo reparo de su real trascendencia, generando más bien mayor alarma en la población y la consiguiente demanda exagerada de atención en los centros de salud por la sola presencia de síntomas banales que equivocadamente eran asociados con el SGB.

El grueso de las cifras se refiere a los casos sospecha, mas no a los casos definidos. Así, la paciente RPZ de 72 años ingresó a un centro de salud de Junín con historia de disminución de

I. Médico internista. Past presidente de la SPMI fuerza en las piernas y hormigueo en las pantorrillas que se interpretó como "parestesias". De inmediato fue calificada como caso sospecha de SGB y pasó a engrosar la estadística. Un día después, una anamnesis más acuciosa determinó que la supuesta falta de fuerza en las piernas se debía al dolor de rodillas por una artrosis que le recrudecía en invierno y el "hormigueo" era prurito originado por un eczema varicoso. Todos los especialistas coinciden en que este síndrome de mediación inmune puede aparecer en sujetos predispuestos una a seis semanas después de la ocurrencia de un proceso infeccioso. Aun cuando hay algunos casos reportados que lo relacionan al virus Zika, por lo general la gran mayoría ocurre posterior a un proceso gastrointestinal o respiratorio que involucra agentes como Campilobacter jejuni, Mycoplasma pneumoniae, virus Coxsakie, enterovirus, citomegalovirus, virus Epstein Barr, entre otros. ${ }^{4-6}$

Todos estos agentes tienen en común la transmisibilidad fecaloral y/o respiratoria, por tanto, hay una interrogante que puede plantearse: ¿La elevación inusual de casos de SGB se debe a un incremento de los factores ambientales y de salubridad que conllevan el aumento de infecciones gastrointestinales y respiratorias? De ser así, ¿el Decreto de Estado de Emergencia debería ser para enfrentar los casos nuevos de SGB o para luchar contra los factores que atentan contra la salud pública respecto a las infecciones transmisibles, particularmente respiratorias y gastrointestinales? Es probable que los casos reportados de SGB sean solo la punta del iceberg de un problema mayor y que debajo de la superficie exista algo que se pretende ignorar y la opinión pública desconoce. Todos hablan del SGB pero ningún medio de comunicación menciona que a junio de 2019 ya llevamos acumulados más de 11000 casos de neumonía en menores de cinco años y más de 9000 casos de neumonía en mayores de 50 años, que en 2018 hubo 476000 casos de enfermedad diarreica aguda en menores de cinco años y que a junio de 2019 el acumulado ya es $220000 .^{2}$ Es probable que detrás de estas cifras existan los factores socioeconómicos y de salubridad que todos conocemos, los cuales, ineluctablemente conllevan a la malnutrición, inadecuado servicio de 
alcantarillado y agua potable, déficit en el acceso universal a los servicios de salud y escasa educación de la población referente a los cuidados básicos de la salud, entre otros. No es casualidad que la mayor cantidad de casos reportados del SGB haya ocurrido en zonas económicamente deprimidas de Piura, Cajamarca, La Libertad, Junín y en distritos de Lima, como Comas, Puente Piedra, San Martín de Porres y San Juan de Lurigancho. ${ }^{\text {? }}$

Se me ocurre pensar que algo similar ocurre con el publicitado tema de la anemia. A través del Minsa, el Estado ha iniciado una lucha frontal contra la anemia, mal que aqueja a más del $40 \%$ de la población infantil. Sin embargo, todos sabemos que la anemia crónica ocurre por lo general a consecuencia de un estado de malnutrición producto de la situación socioeconómica que nos aqueja. Por tanto, ¿Para combatir la anemia es suficiente repartir caramelos de hierro y alentar la ingesta de alimentos ricos en él? No está mal que el Estado decrete una lucha de articulación multisectorial contra la anemia infantil que involucra a los sectores de Salud, Vivienda, Educación, Producción, entre otras instituciones públicas, ${ }^{8}$ pero si todo el esfuerzo desplegado es solo para atacar en forma paliativa la punta del iceberg de un problema mayor, los resultados a largo plazo respecto al estado nutricional integral de la población probablemente no sean muy alentadores.

La mejora significativa de los indicadores de salud requiere una política de Estado dirigida a elevar paulatinamente el nivel socioeconómico de la población, mantener un efectivo programa de vacunación con la mayor cobertura posible, lograr el acceso a los servicios de salud de toda la población y mejorar en forma paralela los índices de educación y seguridad ciudadana en todos sus aspectos. De lo contrario, no solo tendremos cada año más casos de SGB sino también mayores índices de desnutrición (anemia incluida), tuberculosis, neumonía, enfermedad diarreica, muerte materna, entre muchos otros.

\section{REFERENCIAS BIBLIOGRÁFICAS}

I. Centro Nacional de Epidemiologia. Prevención y Control de Enfermedades. Minsa. URL disponible en: https://www.dge.gob.pe/portal/

2. Sala virtual de situación de salud. Minsa URL disponible en: http://www.dge. gob.pe/salasituacional/sala/index/SALA VIGILA/I4I

3. Decreto Supremo $N^{\circ}$ 0I3-2019-SA. $0 \overline{8}$ de junio de 2019. URL disponible en: https://www.gob.pe/institucion/minsa/normas-legales/279|23-0|3-2019-sa-elperuano

4. Yuki N, Hartung HP. Guillain-Barré Syndrome N Engl J Med 20I2; 366: 22942304

5. Rae Grant A. Guillain-Barré Syndrome. Dynamed Plus. EBSCO Health. Produced in collaboration with American College of Physicians. URL disponible en: http://www.dynamed.com/topics/dmp AN TI I6758/GuillainBarre-syndrome

6. Rebolledo-García D, González-Vargas PO, Salgado Calderón I. Síndrome de Guillain-Barré: viejos y nuevos conceptos. Med Int Méx. 2018 ;34(I):72-81.

7. Sistema de vigilancia epidemiológica del Centro Nacional de Epidemiologia Prevención y Control de Enfermedades. Semana Epidemiológica N. ${ }^{\circ} 24$ (actualizado al 13 de junio 2019). Minsa. URL disponible en: https://www.dge. gob.pe/

8. Decreto Supremo que aprueba el Plan Multisectorial de Lucha contra la Anemia. DS 068-2/8-PCM. URL disponible en: http://www.midis.gob.pe/ dmdocuments/DS_N_068_2018_PCM.pdf 